\title{
INVESTIGATION ABOUT THE MANUFACTURING TECHNIQUE OF THE COMPOSITE CORNER FITTING PART
}

\author{
Peng Wang*, Xavier Legrand, Damien Soulat
}

\author{
University of Lille, ENSAIT, GEMTEX laboratory, F-59056, France \\ * Corresponding author. Tel.: +33 3202589 47. Fax.: +33 320256461. \\ E-mail: peng.wang@ensait.fr, xavier.legrand@ensait.fr, damien.soulat@ensait.fr
}

\begin{abstract}
:
Textile composite reinforcement forming has been employed in many aeronautic industries as a traditional composite manufacturing process. The double-curved shape manufacturing may be difficult and can lead to defects when the composite parts have high curvatures and large deformations. Compared with the textile composites forming, surface $3 D$ weaving can demonstrate directly the geometry of final composite part without the stages involved in $2 D$ product. The weaving in three directions is completely designed and warp and weft yarns are always perpendicular to the surfaces of the final 3D ply. These two manufacturing techniques are applied to produce an important piece of aircraft: the corner fitting. The 3D weaving results are compared with the experimental forming by a punch as same geometry as the corner fitting part. The conveniences and limits of each technique are investigated. The comparisons show particularly a perfect final $3 D$ fabric with homogeneous fibre volume fraction performed by the surface $3 D$ weaving technique.
\end{abstract}

\section{Keywords:}

Manufacture, Weaving, Textile Composite, Forming, 3D Fabric, Corner Fitting

\section{Introduction}

The direct composite manufacturing process called Liquid Composite Molding (LCM) [1,2] has become popular for producing structural polymer-based composites. In this process, a liquid resin progresses through the dry fibrous preforms as the injection under some pressure (Resin Transfer Molding (RTM) process) and the infusion by a vacuum at the vent of the system (Liquid Resin Infusion/Resin Film Infusion). LCM process has been employed in many aeronautic industries to manufacture large, thick or complex aircraft structural parts. Especially RTM process has shown the potential to produce complex composite parts with double curvatures. At present, around $5-10 \%$ of composite parts are produced by this direct process and the current trend is clearly increasing.

The preliminary phase in LCM process concerns the preforming stage. Forming of textile preform stacking has been described by some studies as this step has a strong influence on the resin flow impregnation, by the modification on the permeability [3-7], and on the characteristics of the final composite part $[8,9]$. In case of complex preforming shapes, the consequences of the choice of the process parameters, as the blank holder pressure or punch's shape, on the feasibility to preform fabrics are described by numerical [10-15] or experimental approaches [16-22]. These process parameters influence the deformed state of the preform and consequently the generation of defects. An optimal preform should be free of defects [23], such as wrinkles [24-28] or buckles [16], with no misalignment of fibres according to the orientation expected and spatial homogeneity of the fibre density. The traditional process, carried out by classical tools as blank holder, punch and die [29-31], conduced to deform initial flat dry fabrics to a specific shape an. This traditional automation step is fast (in the range of one minute). But for double-curved shape manufacturing the control of the process parameters may be difficult and can lead to defects, such as wrinkling, undulation, fibre fracture and porosities, when the composite parts have high curvatures and large deformations. On the other hand, an alternative to this traditional process concerns weaving the yarns directly on the three-dimensional (3D) surfaces. The surface 3D weaving process is based on the traditional weaving technology [32-39], but in our case, instead of weaving flat fibrous preform, we use the method to weave directly the shape of the final preform. Compared with the traditional preforming step, the main advantage of this manufacturing process is obtaining directly the preform from threads without deformation of the woven fabrics. The weaving in three directions could be completely designed.

As an important piece of planes, the corner fitting part ensures the link between the plane body and wings (Figure 1). This aircraft component is typically made of aluminium. As weight saving is a key issue for aerospace industry, it is interesting to replace the aluminium corner fitting piece by a composite one, e.g. carbon/epoxy. In this paper, two important manufacturing techniques, surface $3 \mathrm{D}$ weaving and textile reinforcement forming, will be applied to produce a corner fitting composite part, and then a comparison between these two techniques will be performed. Some quality criteria of the deformed fabric will be analysed, in particular, the orientation of yarns and possible manufacturing defects. The conveniences and limits of each technique will be investigated. The analysis will exhibit a perfect corner fitting structure with homogeneous fibre volume fraction performed by the surface 3D weaving technique. 


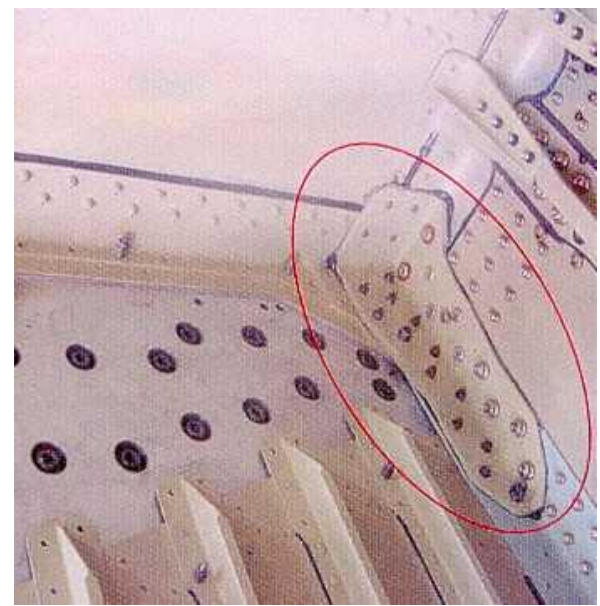

(a)

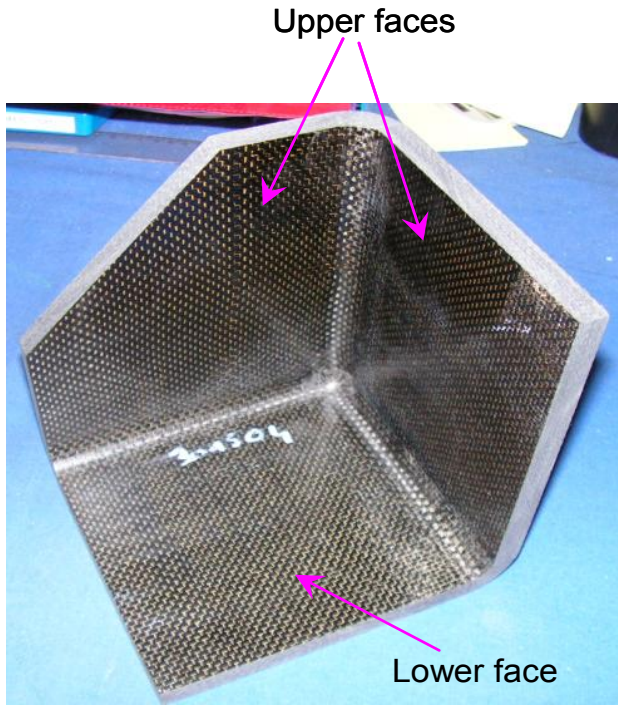

(b)

Figure 1. The aluminum (a) and composite (b) Corner Fitting parts.

\section{3D weaving process}

\subsection{The traditional weaving technique}

The traditional weaving technique produces essentially flat fabric. In order to perform a 3D geometry, a well-known technique, the pocket weaving technique is proposed first, as this textile technique is the only classical one to define a $3 D$ structure in the technical history of weaving [40].

It is possible to obtain the final geometry of the $0^{\circ} / 90^{\circ}$ or $-45^{\circ} / 45^{\circ}$ corner fitting plies from a flat double fabric by using the pocket weaving technique as shown in Figure 2. The orientations of the fibres on each face are almost correct. On the contrary, the continuity of fibres between each of two faces cannot be assured. In this case, it is necessary to develop a new 3D weaving method to control the orientations and assure the continuity of fibres.

\subsection{The surface 3D weaving method}

As the orientations of fibres must be assured $\left(0^{\circ} / 90^{\circ}\right.$ or $\left.-45^{\circ} / 45^{\circ}\right)$ and combined with complete continuity, a new device to carry out automatically the surface $3 \mathrm{D}$ weaving process has been developed [41-43]. The textile reinforcement ply is made of carbon fibres (Toho-Tenax, $12 \mathrm{~K}$ ). The corner fitting $3 \mathrm{D}$ fabric with the fibre direction of $0^{\circ} / 90^{\circ}$ can be manufactured in the following three main steps.

The first step: as for traditional loom, the first step for manufacturing fabric concerns the fibre beaming and picking the direction $X$ (Figure 3a).

The second step: this step is still as in a traditional weaving loom process. The fibres in the direction $Y$ are weaved with the ones in the direction $X$ to build the face 1 (Figure $3 b$ ).

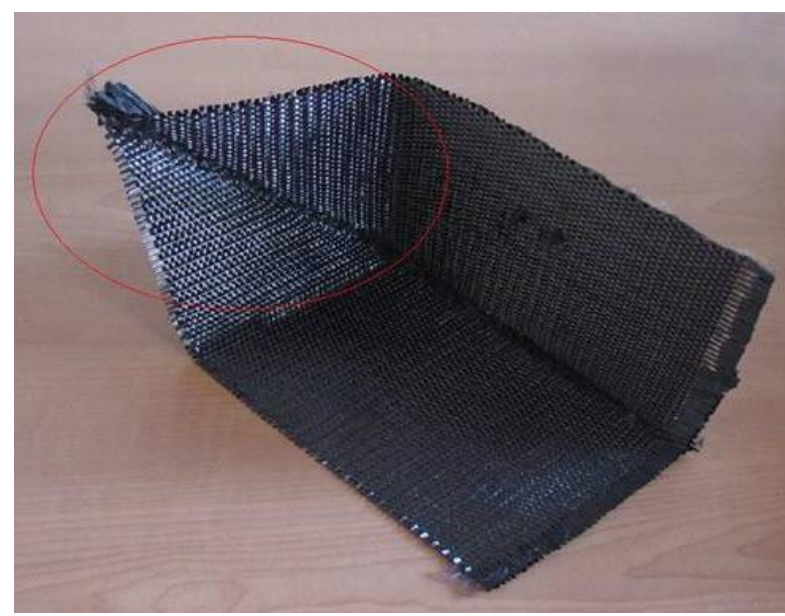

Internal view of corner

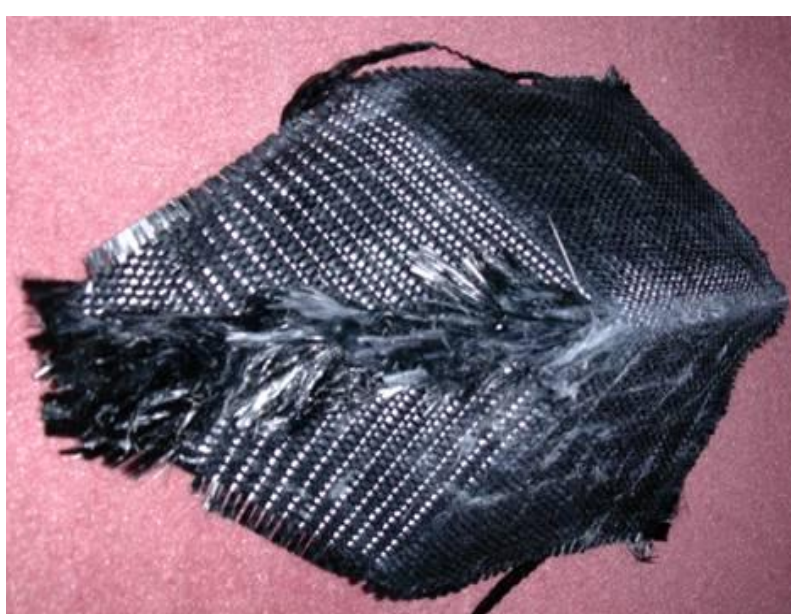

External view of corner

Figure 2. The corner fitting $3 \mathrm{D}$ ply with discontinuity obtained by the pocket weaving technique. 
Phase 1 (1D)

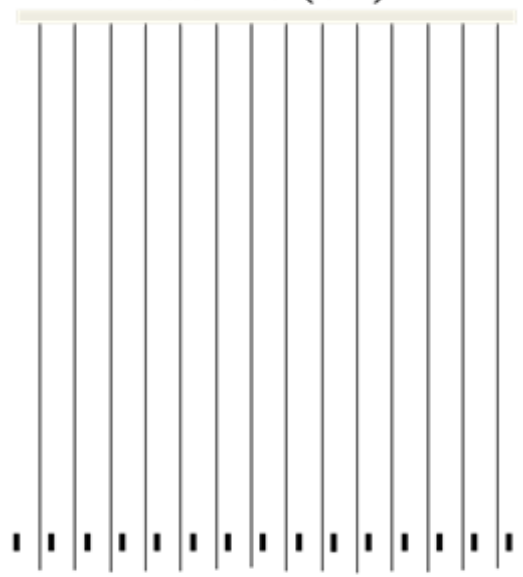

picking, drawing, ...

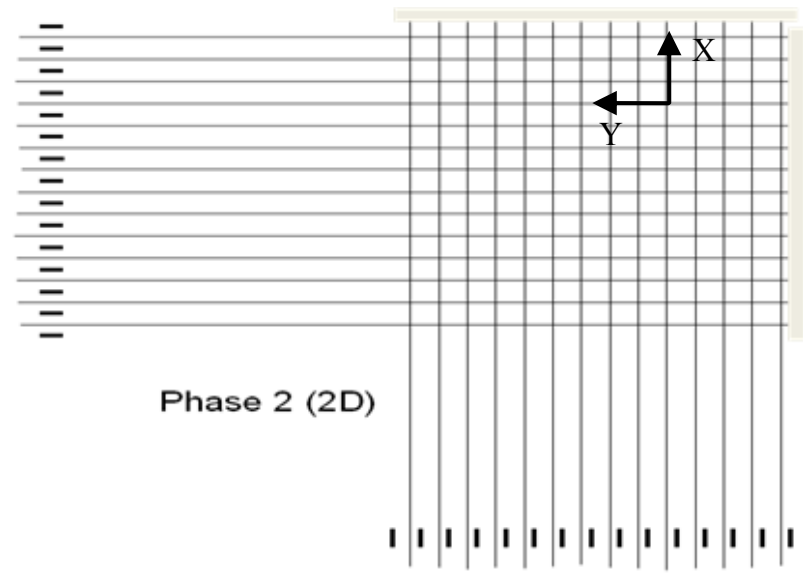

... 2D weaving.

(a)

(b)

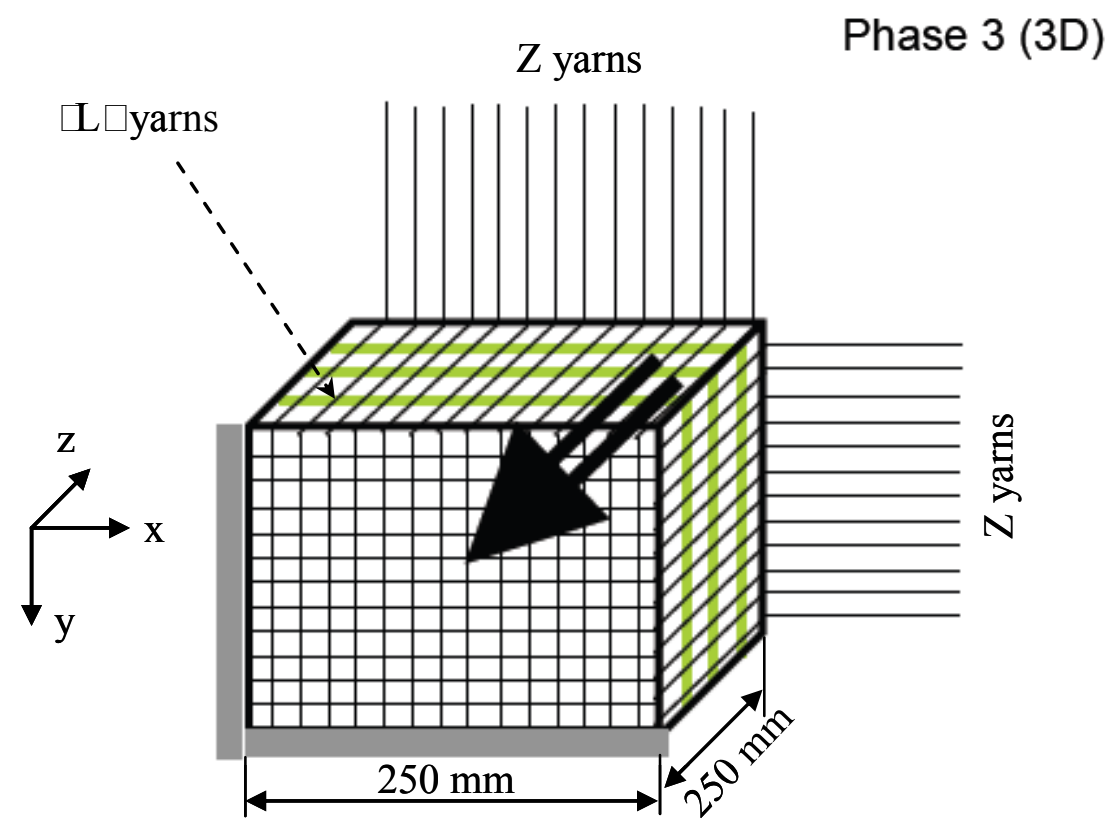

(c)

Figure 3. The different steps of surface 3D weaving process.

The third step: the $Z$ fibres are generated automatically by the free fibres in the directions $X$ and $Y$. Then $X$ and $Y$ fibres are weaved with $Z$ fibres as shown in Figure 3c. The insertion of $X$ and $Y$ fibres is not rectilinear but in the path of "L". In this way, the two faces (the faces 2 and 3) can be constructed at the same time.

The desired orientations of fibre are set by controlling the tow tension during the whole structuring (interlacing) process, which is a traditional solution used in the textile industry. The $X$ and $Y$ fibres produced in the steps 1 and 2 are under tension. In order to guarantee the same tension force on each tow, a spring is employed for each loop of carbon tow during the step 3. All the $X$ direction springs are connected together by a transverse bar self-controlled on tension to assure global tension applied on the $X$ tows. Each "L" weft (inserted tow during the step 3 ) is also tensioned after its insertion between $X$ and $Y$ tows. Therefore, the tow is maintained in its right place and the desired orientations could be assured.

The $-45^{\circ} / 45^{\circ}$ corner fitting 3D fabric can be produced similarly in the way presented previously. The $X$ and $Y$ fibres are posed initially $-45^{\circ} / 45^{\circ}$. Then the " $L$ " fibres are woven with $X Y$ fibres following $-45^{\circ}$ and $45^{\circ}$ directions (Figure 4). The final 3D corner fitting plies with the fibre direction of $0^{\circ} / 90^{\circ}$ and $-45^{\circ} / 45^{\circ}$ are shown in Figure 5. There are no winkles observed in these final 3D surface structures. The fibres in warp and weft directions stay perfectly perpendicular to the three faces and the continuity between faces is free from defects. 


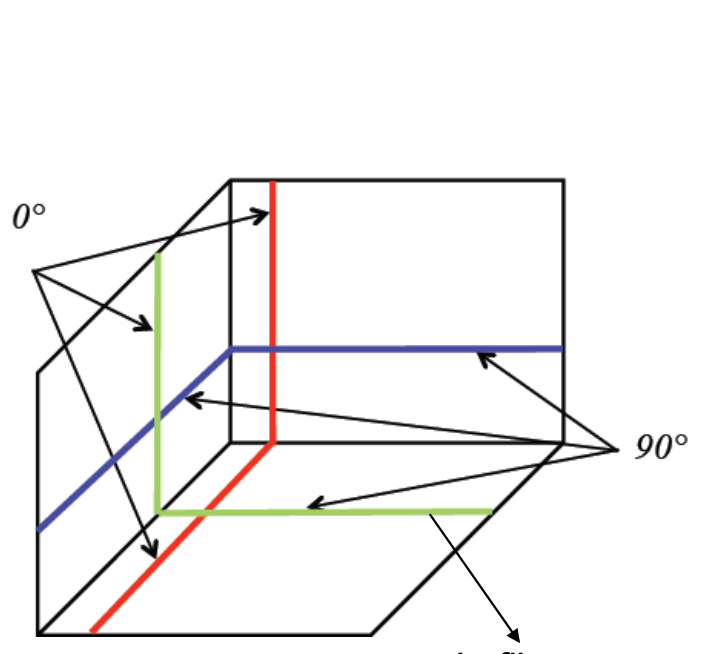

$\mathbb{L} \square$ fibres

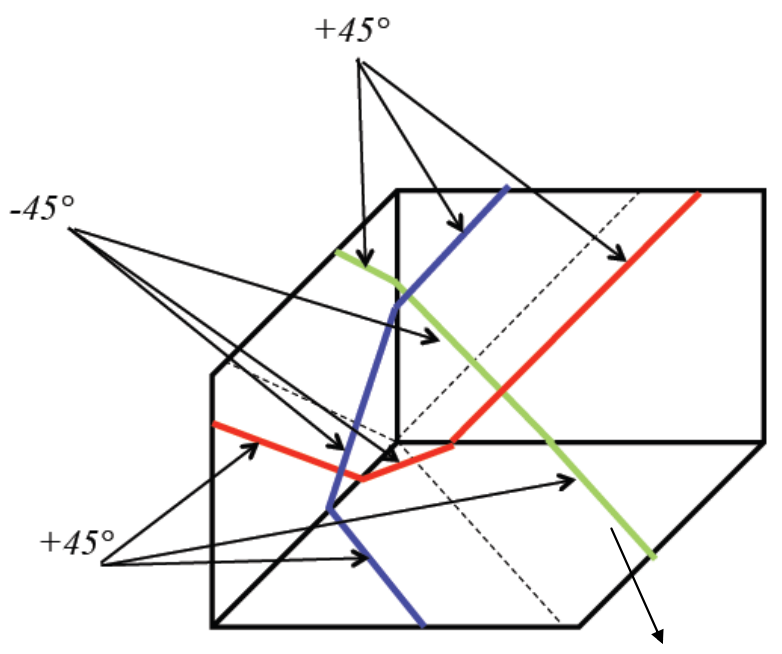

$\mathbb{L} \square$ fibres

Figure 4. The directions of fibres in the $0^{\circ} / 90^{\circ}$ and $-45^{\circ} / 45^{\circ}$ plies.

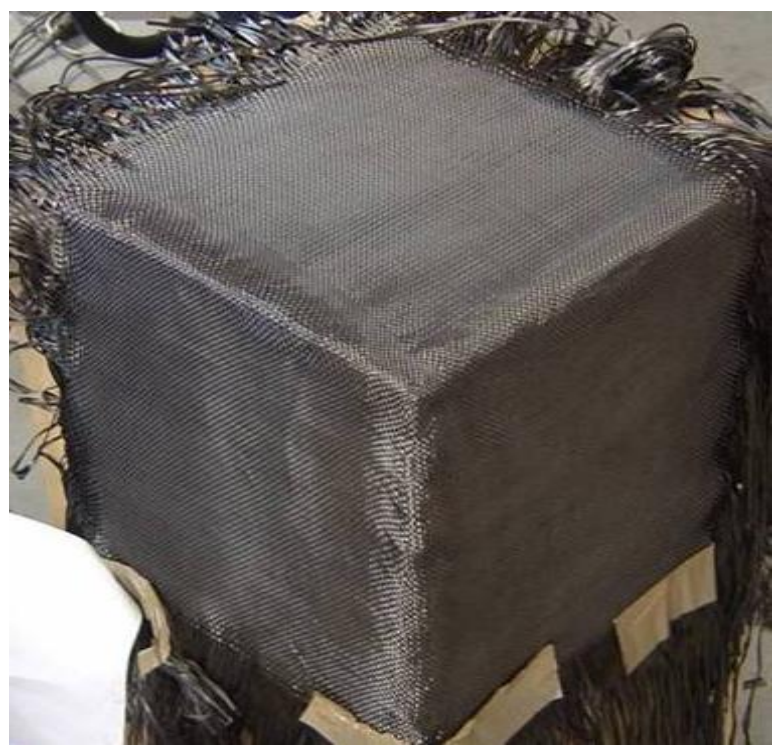

[0 190$]$ ply

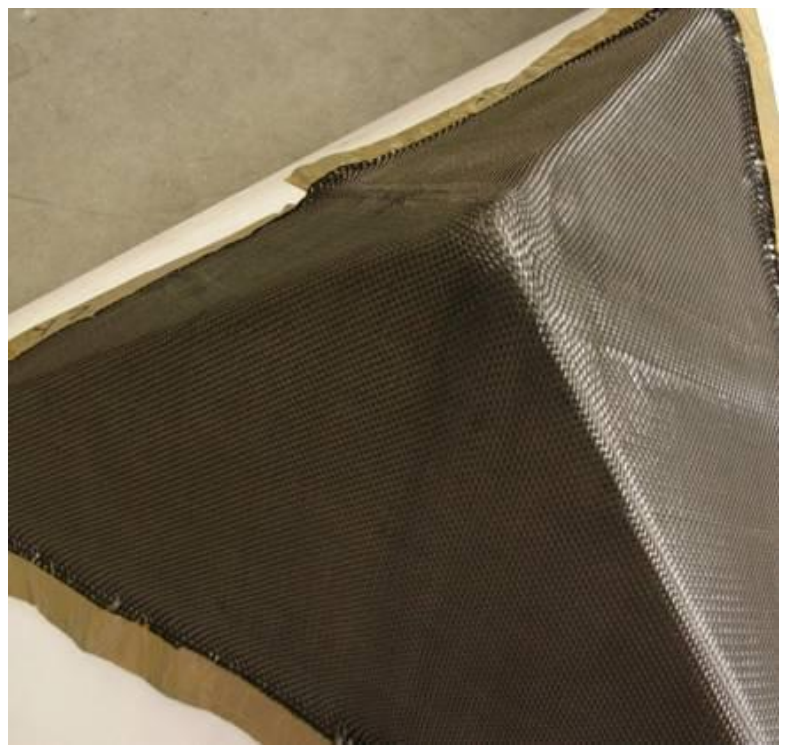

$[-45 \square 45]$ ply

Figure 5. The 3D corner fitting plies obtained by surface 3D weaving process.

The $0^{\circ} / 90^{\circ}$ and $-45^{\circ} / 45^{\circ} 3 \mathrm{D}$ plies are produced and then laminated together (about 20 plies). The final carbon/epoxy composite corner fitting can be carried out by RTM process and is shown in Figure $1 \mathrm{~b}$. The surface $3 \mathrm{D}$ weaving technique defined a new way of designing the textile reinforcement for composite materials. Through this technology, 3D preforms from the fibre bobbin to the $3 \mathrm{D}$ pieces are made without the step of preforming. Indeed, the main advantage of this new technique is the control throughout the process of the orientation of the carbon tow. The preform is free from any local or global misalignment. Moreover, the manufacture of the preform is made in a single operation (divided into three simple steps) very similar to traditional weaving. This is a direct process to obtain the 3D preform. Also, this new technique limits the tows' damage because they are less stressed than by the traditional weaving technique and preforming process. The only noted inconvenience is that because this new technology is still at a laboratory-scale, productivity is limited.

\section{Textile composite reinforcement forming}

\subsection{Experimental set-up}

The experimental forming with a tetrahedral punch is performed on a specific preforming device developed by GEMTEX laboratory and is shown in Figure $6[44,45]$. This device permits analysing the possibilities of the double-curved shape manufacturing with a given textile reinforcement in different forming conditions (shape and thread of punch, position and pressure of blank holder, etc). The given textile fabric is placed between the blank holder and die. Four pneumatic jacks apply 
an adjustable pressure on blank holder ( $0.1 \mathrm{MPa}$ in our corner fitting preforming). In order to monitor the important forming parameters by optical measurement such as the material draw-in, intraply shearing and wrinkles, the "open-die" forming system is used. An electric jack linked to the punch imposes a movement and a load sensor acquires the punch force during the forming. Figure 7 describes the dimensions of the punch used in experimental forming.

\subsection{Corner fitting preforming}

Figure 8 shows the specimen used in corner fitting preforming. This two-dimensional (2D) woven fabric was produced by using the same yarns and in the same machine as the manufacturing of 3D corner fitting fabric presented in Section 2. The main material proprieties of the fabric are noted in Table 1 and the surface dimensions of specimen are $300 \times 300 \mathrm{~mm}$.

The preforming of the corner fitting with $0^{\circ} / 90^{\circ}$ and $-45^{\circ} / 45^{\circ}$ plain weave plies corresponding to a $65 \mathrm{~mm}$ displacement of punch is shown in Figure 9. The warp and weft directions on the deformed plies are figured out. The preforms are obtained without defects as the rupture or the buckle of the yarns. Moreover, no wrinkling is observed in these preforming tests. As one of the most common flaws that occurs during textile composite forming, wrinkling depends not only on the fabric characteristics but also on the manufacturing parameters $[23,24]$.

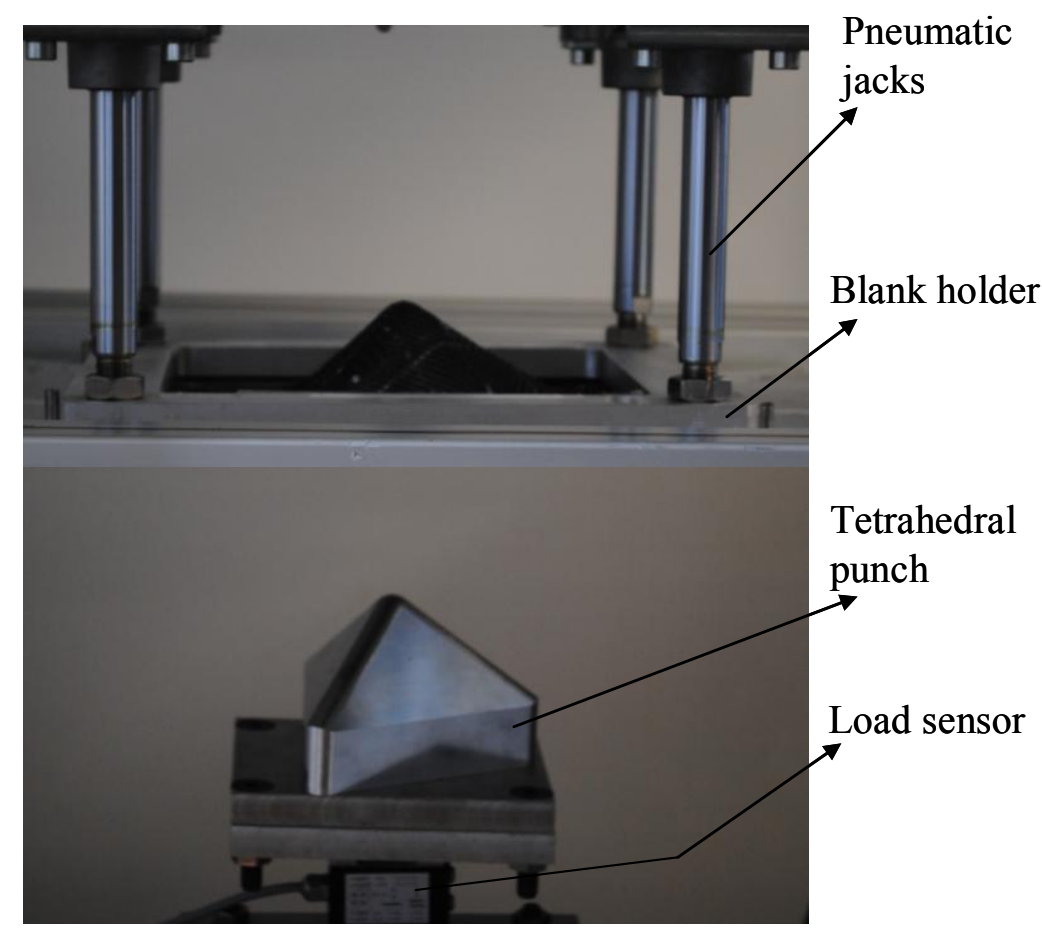

Figure 6. The experimental forming device with a tetrahedral punch.
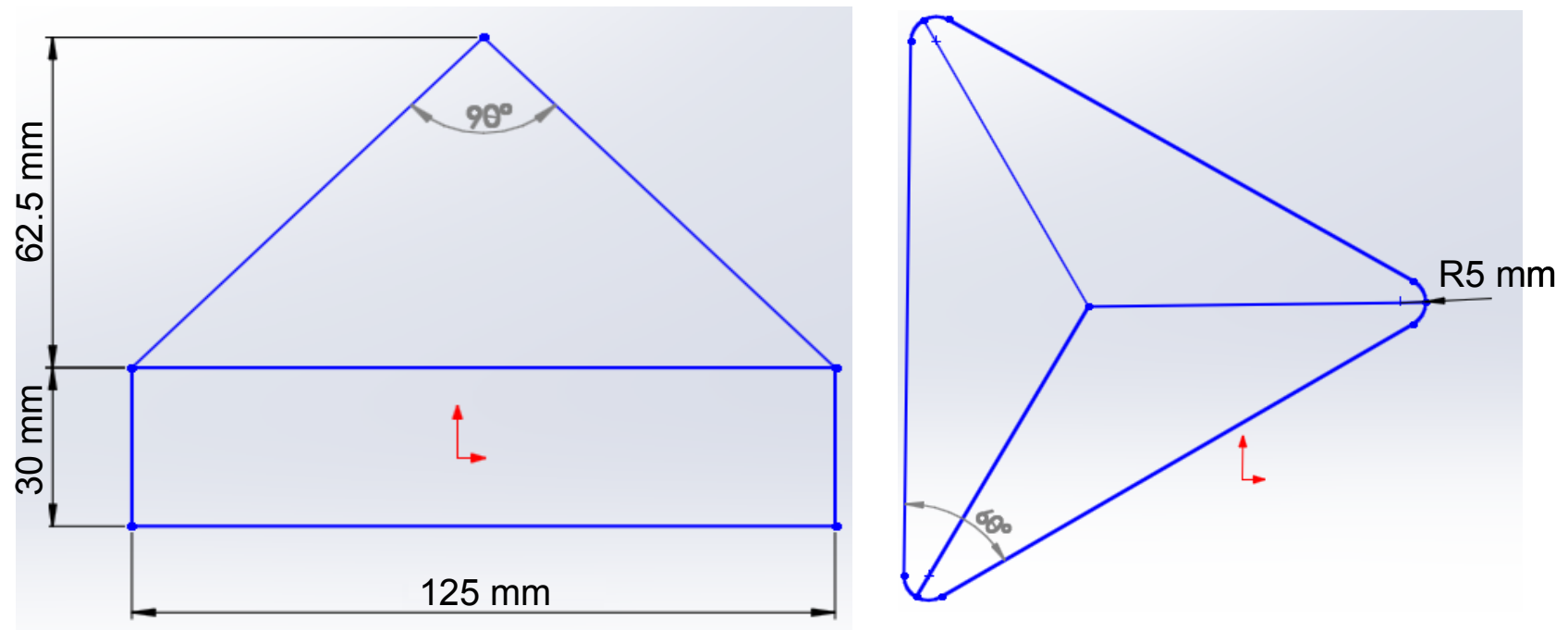

Figure 7. The dimensions of tetrahedral punch. 


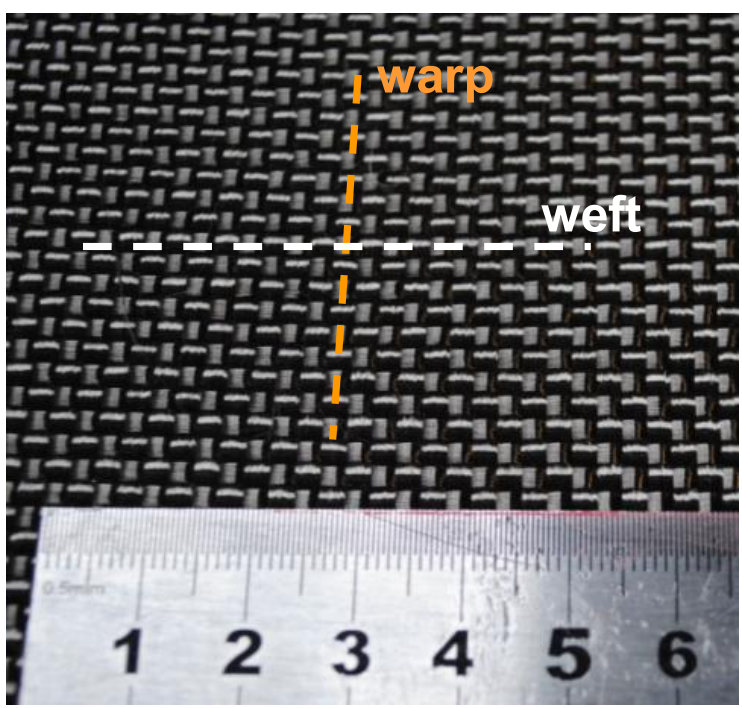

Figure 8. The plain weave fabric used in experimental preforming.

Table 1. The principle material proprieties.

\begin{tabular}{|c|c|}
\hline Type of fabric & Plain weave \\
\hline Manufacturer of filaments & Toho-Tenax \\
\hline Fibres & $12 \mathrm{~K}$ Carbon \\
\hline Yarns (warp/weft) & 800 tex / 800 tex \\
\hline Areal density of fabric $(\mathrm{g} / \mathrm{m} 2)$ & $500 \pm 5 \%$ \\
\hline Thickness of fabric $(\mathrm{mm})$ & 0.1 \\
\hline Number of warp yarns per $\mathrm{cm}$ & 5 \\
\hline Number of weft yarns per $\mathrm{cm}$ & 5 \\
\hline
\end{tabular}

\section{Discussion}

The two technologies, surface 3D weaving and textile reinforcement forming, applied to manufacture the corner fitting part were demonstrated in the previous sections. The 3D corner fitting ply can be obtained directly by the surface 3D weaving process: the yarns directions are completely under control. However, the textile composite forming is based on the $2 \mathrm{D}$ fabric. The angle between warp and weft yarns is not constant due to different local in-plane shearing effects.

Figures 10 and 11 show the warp and weft directions of the deformed $0^{\circ} / 90^{\circ}$ and $-45^{\circ} / 45^{\circ}$ plies performed by surface $3 \mathrm{D}$ weaving and experimental forming, respectively. The warp and weft yarns remain strictly perpendicular in 3D corner fitting ply performed by 3D weaving process (Figures 10a and 11a). Consequently, the local fibre volume fraction of the fabric is constant. Regarding the preforming results, the angle between warp and weft yarns is changed due to in-plane or out-of-plane curvatures in the fabric. There is only a small zone where warp and weft yarns are (or quasi) perpendicular on each face of deformed ply (a small zone with zero in-plane shear angle around the middle line in Figures 10b and 11b). Furthermore, a positive in-plane shear angle (the angle between warp and weft yarns $<90^{\circ}$ ) in the left zone and a negative in-plane shear angle (the angle between warp and weft yarns $>90^{\circ}$ ) in the

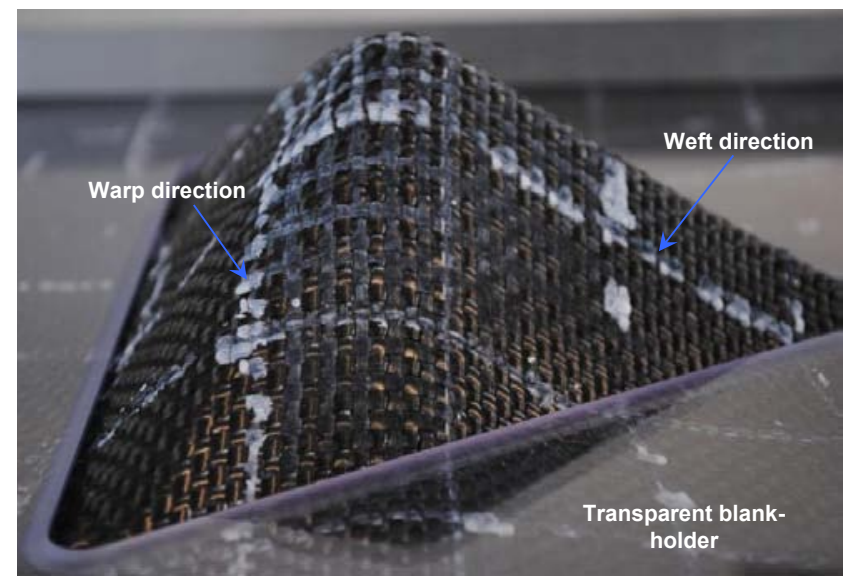

(a)

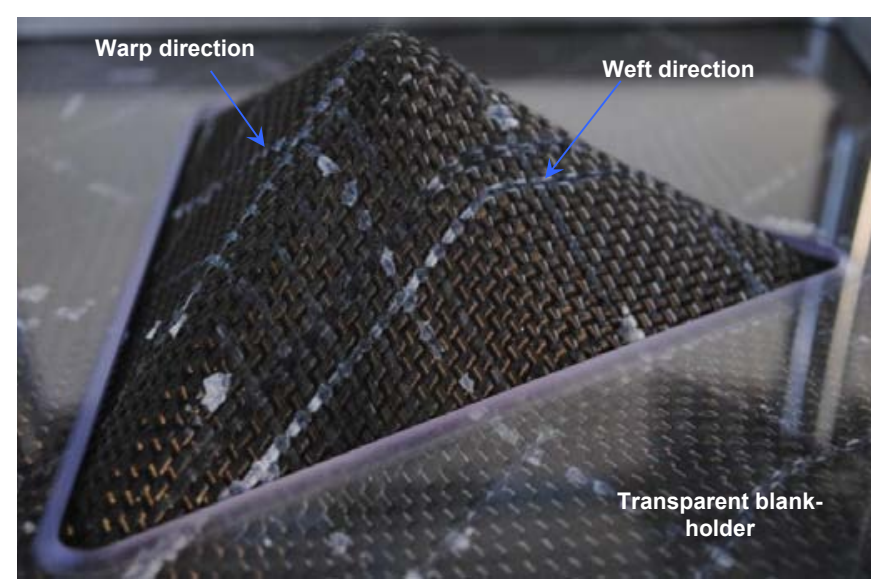

Figure 9. The experimental forming with $0^{\circ} / 90^{\circ}$ (a) and $-45^{\circ} / 45^{\circ}$ (b) plain weave fabrics.

right zone on both $0^{\circ} / 90^{\circ}$ and $-45^{\circ} / 45^{\circ}$ deformed plies can be observed (Figures 10b and 11b). The in-plane shear angle can reach a maximum $25^{\circ}$ after forming in both left and right zones on the deformed $-45^{\circ} / 45^{\circ}$ ply. On the deformed $0^{\circ} / 90^{\circ}$ ply, the maximum in-plane shear angle of $25^{\circ}$ and $20^{\circ}$ can be observed in the left and right zones, respectively. These changes in the angle between warp and weft yarns lead to a variation of fibre volume fraction and local permeability of the textile fabric. Subsequently, it could result in a non-homogenous flow during the resin infusion or injection stage. In this case, it will have a negative influence on mechanical performance of the final composite part. As an essential manufacturing parameter in LCM processes, the permeability of the preform should be well controlled.

Wrinkling is a global phenomenon depending on all strains and stiffness and on boundary conditions of textile reinforcement forming [24]. It is frequent to experience the wrinkling phenomenon in both dry textile fabric $[16,24]$ and prepreg composites forming [46] due to the possible relative motion of fibres and internal composition of textile reinforcement, causing a very weak bending stiffness $[23,24,47]$. Another forming example with a tetrahedral punch was performed by Allaoui et al. [16] who presented that it is possible to observe the wrinkles when a weak blank holder pressure was used (Figure 12a). The blank holder can create sufficient tensions to 

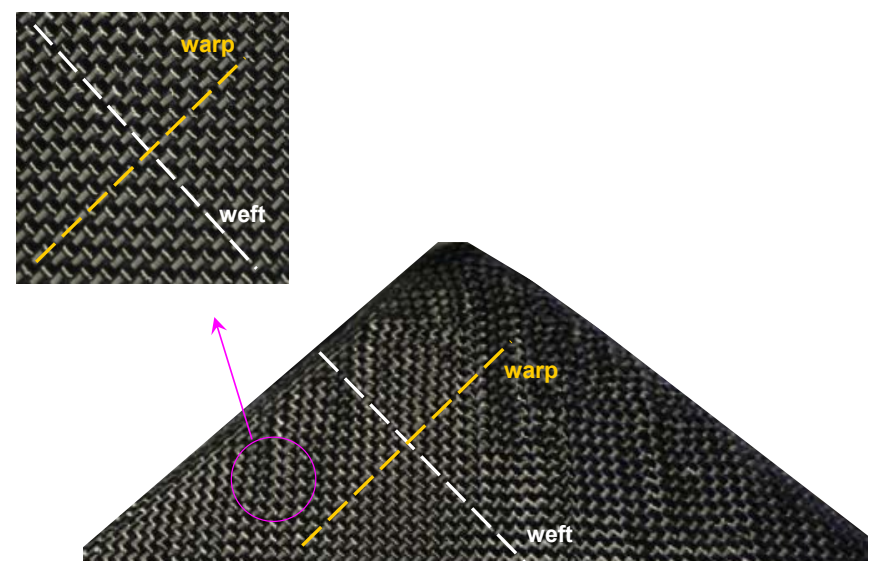

(a)

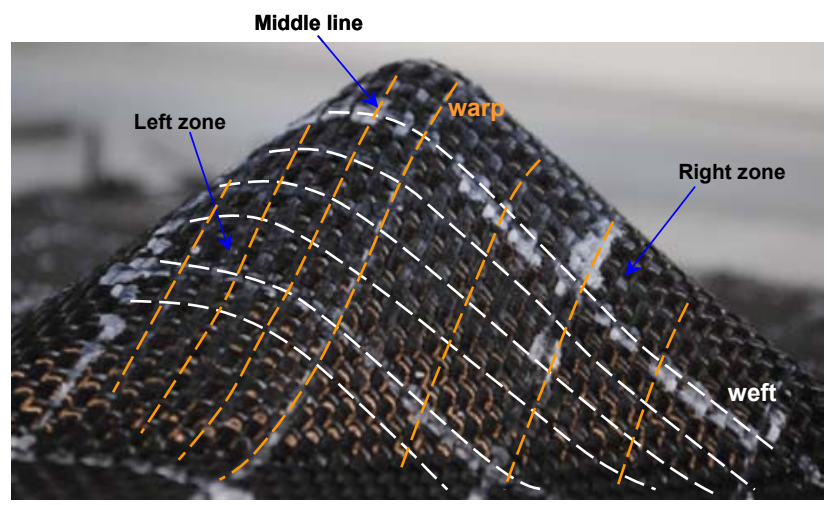

(b)

Figure 10. The yarns' directions of the deformed $0^{\circ} / 90^{\circ}$ ply obtained by the surface 3D weaving (a) and the experimental preforming (b).

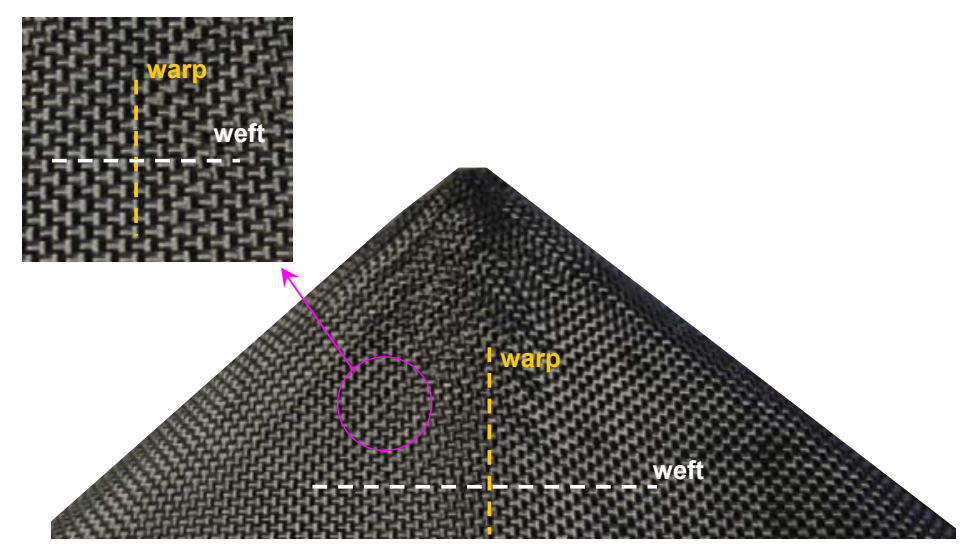

(a)

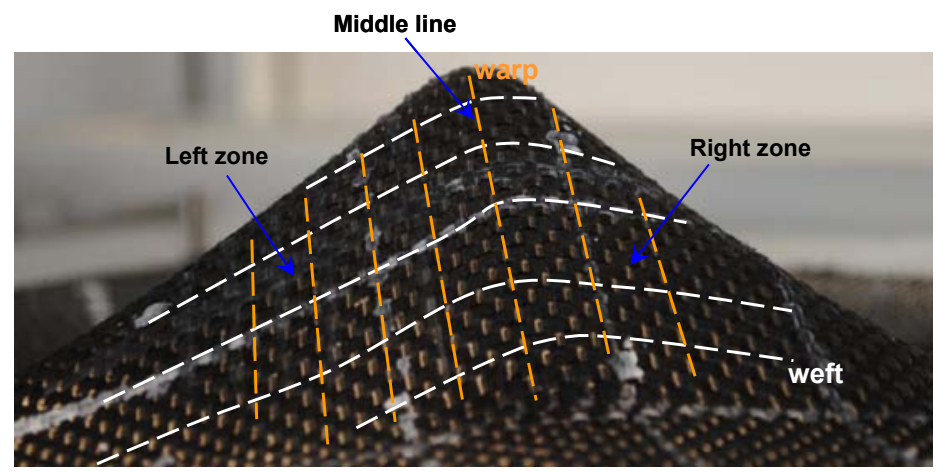

(b)

Figure 11. The yarns' directions of the deformed $-45^{\circ} / 45^{\circ}$ ply obtained by the surface $3 \mathrm{D}$ weaving (a) and the experimental preforming (b). 


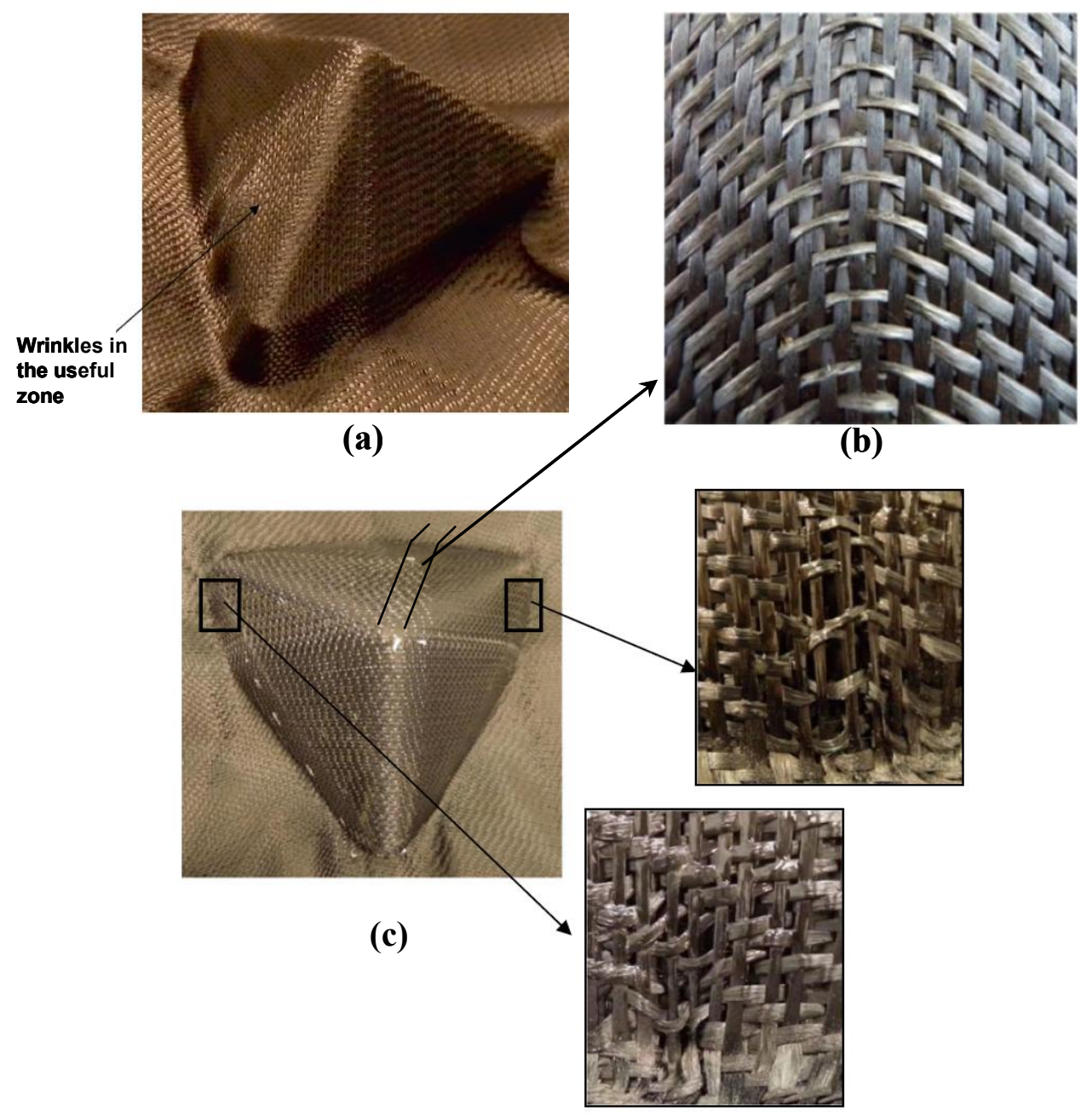

Figure 12. The possible defects in textile reinforcement forming with a tetrahedral punch, (a) the wrinkling [15], (b) the buckling and (c) the sliding of network [37].

avoid wrinkling even if it leads to the large in-plane shear angles. On the contrary, other forming defects such as the buckles (Figure 12b) and the slippage of networks (Figure 12c) could be generated under a high blank holder pressure [48]. The surface 3D weaving can avoid totally the forming defects mentioned previously on all of the surfaces of corner fitting part because of warp and weft yarns being always perpendicular and the tensions of yarns under control. These defects, in particular the wrinkles, developed in the useful zone will modify strongly the local permeability of preform and influence negatively the resin impregnation, which will reduce the mechanical performance of composite piece. Consequently, it is important to optimise the forming processes to minimise the wrinkling at least in the useful zone.

\section{Conclusions}

The surface $3 D$ weaving technique and its application to a corner fitting structure have been described. As a novel manufacturing technology of the composite materials, the surface $3 D$ weaving technique seems very promising. It is possible by using this technique to produce the $3 \mathrm{D}$ composite fabrics with quite complex geometry. Compared with the traditional forming process, the surface $3 \mathrm{D}$ weaving is a direct route to avoid certain manufacturing defects, such as wrinkling, porosities and slippage of the network. On the contrary, the 3D weaving process is time-consuming and difficult to implement.

Composites forming process is fast and more developed. It is used widely for dry textile reinforcements. Thermoforming under the resin cure temperature can be adapted not only for thermoplastic but also for thermoset prepreg materials $[20,46]$. However, the forming/thermoforming can lead to various defects depending on the process parameters (tool loads, blank holder forces, temperature, etc). Therefore, it is important to predict the feasible forming/thermoforming conditions by numerical simulation [13-16,49-53]. Compared with the 3D weaving technique, composites forming is more efficient for the manufacturing of multilayer laminates and interlock fabric [54]. The 3D weaving can manage well the tension of yarns, which can be an advantage compared with the preforming especially for natural fibres $[17,18,22]$.

The numerical simulation analysis can not only predict the feasible forming condition but also provide some essential forming information to optimise the $3 \mathrm{D}$ weaving process, such as final shape of the laminate, position of the yarns, the angle between the warp and weft directions and the zones with the important interactions among yarns. In a future work, 
the optimisation of surface 3D weaving process by numerical simulation will be carried out.

\section{Acknowledgements}

The support from Airbus France is gratefully acknowledged.

\section{References}

[1] Advani, S.G. Flow and rheology in polymeric composites manufacturing. Amsterdam: Elsevier; 1994.

[2] Rudd, C.D., Long, A.C. Liquid Molding Technologies. Cambridge: Woodhead Pub. Lim.; 1997.

[3] Bickerton, S., Simacek, P., Guglielmi, S.E., Advani, S.G. (1997). Investigaition of draping and its effects on the mold filling process during manufacturing of a compound curved composite part, Compos Part A, 28, 801-16.

[4] Walther, J., Simacek, P., Advani, S.G. (2012). The effect of fabric and fiber tow shear on dual scale flow and fiber bundle saturation during liquid molding of textile composites. Int J Mater Form, 5(1), 83-97.

[5] Arbter, R., Beraud, J.M., Binetruy, C., et al. (2011). Experimental Determination of the Permeability of Textiles: A Benchmark Exercise. Compos Part A, 42(9), 1157-68.

[6] Ouagne, P., Bréard, J. (2011). Continuous transverse permeability of fibrous media. Compos Part A, 41(1), 22-8.

[7] Vernet, N., Ruiz, E., Advan, S., et al. (2014). Experimental Determination of the Permeability of Engineering Textiles: Benchmark II. Compos Part A,doi: http://dx.doi. org/10.1016/j.compositesa.

[8] Lee, S.H., Han, J.H., Kim, S.Y., Youn, J.R., Song, S.Y. (2010). Compression and Relaxation Behavior of Dry Fiber Preforms for Resin Transfer Molding. J. Compos Mater, 44(15), 1801-20.

[9] Skordos, A.A., Aceves, C.M., Sutcliffe, M.P.E. (2007). A simplified rate dependent model of forming and wrinkling of pre-impregnated woven composites. Compos Part $A$, 38, 1318-30.

[10] Lee, J., Hong, S., Yu, W., Kang, T. (2007). The effect of blank holder force on the stamp forming behavior of noncrimp fabric with a chain stitch. Compos Sci Tech, 67(3-4), 357-66.

[11] De Luycker, E., Morestin, F., Boisse, P., Marsal, D. (2009). Simulation of $3 D$ interlock composite preforming. Compos Struct, 88(4), 615-23.

[12] Gereke, T., Döbrich, O., Hübner, M., Cherif, C. (2013). Experimental and Computational Composite Textile Reinforcement Forming: A Review. Compos Part A, 46, 1-10.

[13] Khan, M.A., Mabrouki, T., Vidal-Sallé, E., Boisse, P. (2010). Numerical and experimental analyses of woven composite reinforcement forming using a hypoelastic behaviour. Application to the double dome benchmark. $J$ Mater Process Technol, 210(2), 378- 88.

[14] Peng, X., Rehman, Z.U. (2011). Textile composite double dome stamping simulation using a non-orthogonal constitutive model. Compos Sci Technol, 71(8), 1075-81.

[15] Charmetant, A., Vidal-Sallé, E., Boisse, P. (2011). Hyperelastic modelling for mesoscopic analyses of composite reinforcements. Compos Sci Technol, 71(14), 1623-31.

[16] Allaoui, S., Boisse, P., Chatel, S., Hamila, N., Hivet, G., Soulat, D., Vidal-Salle, E. (2011). Experimental and numerical analyses of textile reinforcement forming of a tetrahedral shape. Compos Part A, 42(6), 612-22.

[17] Ouagne, P., Soulat, D., Tephany, C., Duriatti, D., Allaoui, S., Hivet, G. (2013). Mechanical characterisation of flax based woven fabrics and in situ measurements of tow tensile strain during the shape forming. J Compos Mater, 47, 3501-17.

[18] Capelle, E., Ouagne, P., Soulat, D., Duriatti, D. (2014). Complex shape forming of flax woven fabrics: Design of specific blank-holder shapes to prevent defects. Compos Part B, 62, 29-36.

[19] Harrison, P., Gomes, R., Curado-Correia, N. (2013). Press forming a 0/90 cross-ply advanced thermoplastic composite using the double-dome benchmark geometry. Compos Part A, 54, 56-69.

[20] Yin, H., Peng, X., Du, T., Chen, J. (2013). Forming of thermoplastic plain woven carbon composites: An experimental investigation. Journal of Thermoplastic Composite Materials. doi: 10.1177/0892705713503668.

[21] Haanappel, S.P., ten Thije, R.H.W., Sachs, U., Rietman, B., Akkerman, R. (2014). Formability analyses of unidirectional and textile reinforced thermoplastics. Compos Part A, 56, 80-92.

[22] Ouagne, P., Soulat, D., Moothoo, J., Capelle, E., Gueret, S. (2013). Complex shape forming of a flax woven fabric; analysis of the tow buckling and misalignement defect. Compos Part A, 51, 1-10.

[23] Potter, K., Khan, B., Wisnom, M., Bell, T., Stevens, J. (2008). Variability, fibre waviness and misalignment in the determination of the properties of composite materials and structures. Compos Part A, 39, 1343-54.

[24] Boisse, P., Hamila, N., Vidal-Sallé, E., Dumont, F. (2011). Simulation of wrinkling during textile composite reinforcement forming. Influence of tensile, in-plane shear and bending stiffnesses. Compos Sci Tech, 71(5), 683-92.

[25] Skordos, A.A., Sutcliffe, M.P.F. (2008). Stochastic simulation of woven composites forming. Compos Sci Tech, 68, 283-96.

[26] Zhu, B., Yu, T.X., Teng, J., Tao, X.M. (2009). Theoretical Modeling of Large Shear Deformation and Wrinkling of Plain Woven Composite. J Compos Mater, 43, 125-38.

[27] Bloom, L.D., Wang, J., Potter, K.D. (2012). Damage progression and defect sensitivity: An experimental study of representative wrinkles in tension. Compos Part $B$, 45(1), 449-58.

[28] Hallander, P., Akermo, M., Mattei, C., Petersson, M., Nyman, T. (2013). An experimental study of mechanisms behind wrinkle development during forming of composite laminates. Compos Part A, 50, 54-64.

[29] Chu, T.C., Ranson, W.F., Sutton, M.A., Peters, W.H. (1985). Applications of digital-image correlation techniques to experimental mechanics. Exp Mech, 25(3), 232-34.

[30] Long, A.C., Rudd, C.D., Blagdon, M., Smith, P. (1996). Characterizing the processing and performance of aligned reinforcements during preform manufacture. Compos Part A, 27(4), 247-53.

[31] Lomov, S.V., Ivanov, D.S., Verpoest, I., et al. (2008). Full-field strain measurements for validation of meso-FE 
analysis of textile composites. Compos Part A, 39(8), 1218-31.

[32] Kamiya, R., Cheeseman, B.A., Popper, P., Chou, T.W. (2000). Some recent advances in the fabrication and design of three-dimensional textile preforms: a review. Compos Sci Tech, 60, 33-47.

[33] Mouritz, A.P., Bannister, M.K., Falzon, P.J., Leong, K.H. (1999). Review of applications for advanced threedimensional fibre textile composites. Compos Part A, 30, 1445-61.

[34] Bilisik, K. (2012). Multiaxis three-dimensional weaving for composites: A review. Textil Res J, 82(7), 725-43.

[35] Chen, X., Taylor, L.W., Tsai, L.J. (2011). An overview on fabrication of three-dimensional woven textile preforms for composites. Textil Res J, 81(9), 932-44.

[36] Karahan, M., Karahan, N. (2014). Influence of weaving structure and hybridization on the tensile properties of woven carbon-epoxy composites. Journal of Reinforced Plastics and Composites, 33, 212-22

[37] Bilisik, K., Karaduman, N.S., Bilisik, N.E., Bilisik, H.E. (2013). Textile Research Journal, doi: 10.1177/0040517513499437.

[38] Gokarnesha, N., Alagirusamy, R. (2009). Weaving of 3D fabrics: A critical appreciation of the developments. Textile Progress, 41, 1-58.

[39] Lefebvre, M., Boussu, F., Coutellier, D. (2013). Influence of high-performance yarns degradation inside threedimensional. Journal of Industrial Textiles, 42, 475-88.

[40] Miravete, A. 3-D textile reinforcements in composite materials, CRC Press, 322 pages, 1999.

[41] Legrand, $X$., et al. Tissage tridimensionnel surfacique, Patent No. FR20060054580, 27/10/2006.

[42] Legrand, $X$., et al. Pliage de coins tissés et formation de préformes renforcées. Patent No. FR20060054581, 27/10/2006.

[43] Legrand, X., Boussu, F., Blot, P., Guitard, D. (2009). A new technique of weaving $3 D$ surface application to Carbon/ Epoxy corner fitting plies. Int J Mater Form, 2(Supp/ 1), 185-87.
[44] Najjar, W., Legrand, X., Pupin, C., Dal Santo, P., Boude, S. (2012). A Simple Discrete Method for the Simulation of the Preforming of Woven Fabric Reinforcement. Key Engineering Materials, 504-506, 213-18.

[45] Najjar, W., Legrand, X., Dal Santo, P., Soulat, D., Boude, S. (2013). Analysis of the blank holder force effect on the preforming process using a simple discrete approach. Key Engineering Materials, 554-557, 441-46.

[46] Wang, P., Hamila, N., Boisse, P. (2013). Thermoforming simulation of multilayer composites with continuous fibres and thermoplastic matrix. Compos Part B, 52, 127-36.

[47] Prodromou, A.G., Chen, J. (1997). On the relationship between shear angle and wrinkling of textile composite performs. Compos Part A, 28A, 491-503.

[48] Allaoui, S., Hivet, G., Soulat, D., Wendling, A., Ouagne, P., Chatel, S. (2012). Experimental preforming of highly double curved shapes with a case corner using an interlock reinforcement. Int J Mater Form, DOI 10.1007/s12289012-1116-5.

[49] Hamila, N., Boisse, P., Sabourin, F., Brunet, M. (2009). A semi-discrete shell finite element for textile composite reinforcement forming simulation. Int $J$ Numer Methods Eng, 79, 1443-66.

[50] Durville, D. (2010). Simulation of the mechanical behaviour of woven fabrics at the scale of fibers. Int J Mater Form, 3, 1241-51.

[51] Creech, G., Pickett, A.K. (2006). Meso-modelling of NonCrimp Fabric composites for coupled drape and failure analysis. J Mater Sci, 41, 6725-36.

[52] ten Thije, R.H.W., Akkerman, R., Huétink, J. (2007). Large deformation simulation of anisotropic material using an updated Lagrangian finite element method. Comput Methods Appl Mech Eng, 196, 3141-50.

[53] Yu, W.R., Pourboghrata, F., Chungb, K., Zampaloni, M., Kang, T.J. (2002). Non-orthogonal constitutive equation for woven fabric reinforced thermoplastic composites. Compos Part A, 33, 1095-1105.

[54] Dufour, C., Wang, P., Boussu, F., Soulat, D. (2013). Experimental Investigation About Stamping Behaviour of 3D Warp Interlock Composite Preforms, Applied Composite Material, doi 10.1007/s10443-013-9369-9. 